\title{
Prediction of Flexural Strength of Concretes Containing Silica Fume and Styrene-Butadiene Rubber (SBR) with an Empirical Model
}

\author{
M. Shafieyzadeh ${ }^{1}$
}

Received: 13 February 2013/Accepted: 8 September 2015/Published online: 17 November 2015

(c) The Author(s) 2015. This article is published with open access at Springerlink.com

\begin{abstract}
In the flexural test, the theoretical maximum tensile stress at the bottom fiber of a test beam is known as the modulus of rupture or flexural strength. This work deals with the effects of Silica Fume and Styrene-Butadiene Latex (SBR) on flexural strength of concrete. An extensive experimentation was carried out to determine the effects of silica fume and SBR on flexural strength of concrete. Two water-binder ratios and several percentages of silica fume and SBR were considered. Abrams' Law, which was originally formulated for conventional concrete containing cement as the only cementations material, is used for prediction of flexural strength of these concretes. The aim of this work is to construct an empirical model to predict the flexural strength of silica fume-SBR concretes using concrete ingredients and time of curing in water. Also, the obtained results for flexural strength tests have been compared with predicted results.
\end{abstract}

Keywords Silica fume $\cdot$ SBR $\cdot$ Flexural strength

\section{Introduction}

Nowadays, research on cement matrix materials is focused on the inclusion of additives, admixtures and short fibers, to improve certain physical and mechanical properties. Adherence, permeability, ductility and strength are some of the main research lines on binder materials [1].

M. Shafieyzadeh

shafiey_zadeh@yahoo.com

1 Department of Civil Engineering, Shahid Rajaee Teacher Training University, Tehran, Iran
The flexural strength or modulus of rupture of concrete is determined with simple rectangular beams without any reinforcement submitted to increasing bending until failure occurs. The modulus of rupture is determined from the moment as failures. This knowledge is useful in the design of pavement slabs and airfield runways as flexural tension is critical in these cases.

A most frequently used polymer is Styrene-Butadiene Rubber (SBR). The previous researches showed that SBR modified mortars and concretes had good mechanical properties, with respect to polymer-free materials. Their workability, adhesion to substrate, durability and abrasion resistance can be significantly improved [2-6]. Polymer can form another network in the material, which fills up pores in cement matrix and improves the bonding between aggregates and cement paste [7].

Also, the use of silica fume increases the resistance of concrete against acid and sulfate attack and improves durability of concrete by reducing porosity and permeability of cement paste matrix, it makes the concrete more resistant against abrasive forces and reduces the expansion generated by alkali-aggregate properties [8].

A recent report said the highest values of the thickness reduction of the Interfacial Transition Zone (ITZ) were obtained for the concretes which both silica fume and SBR latex, besides the thickness reduction of the ITZ [9], it is expected some properties of the concrete, such as mechanical strength, elastic modules and permeability are improved.

In this study, the flexural strength is tried to improve with addition of supplementary materials (SBR and silica fume) to concrete. In this research, the combination of wet and dry curing is applied to the polymer-modified silica fume concretes. The benefits of this curing system, completion of hydration of cement matrix in the early curing period and solidification of SBR latex in the dry curing 
during the following curing period [10]. Therefore, the adhesion and strength of both cement matrix and SBR film are developed effective.

A lot of researches investigated the isolated effects of silica fume or SBR on flexural strength [1-4, 7, 10-14] but it seems that few reports on the relationship between flexural strength and ratios of SBR or silica fume to binder materials are found until now. The current empirical equations presented are based on tests of concrete without supplementary cementations materials. The validity of these relationships for concrete with supplementary materials (silica fume, SBR, etc.) should be investigated.

Most of the empirical models used to study the behavior of concrete mixes consist of mathematical rules and expressions that capture relationship between components of concrete mixes. In the present work, the flexural strength is modeled as a function of four variables: the ratios of polymer, silica fume, water to binder materials and time of curing in water. The proposed model is determined based on regression methods. Linear or nonlinear regression methods are conventional methods of predicting the strength of concrete.

\section{Materials}

The materials used in this study were ordinary Portland cement, river sand with a fines modulus of 3.01 and coarse aggregate with a specific gravity of 2.25 . A locally produced ordinary silica fume was used in this investigation. The binder content weighted keep constant $400 \mathrm{~kg} / \mathrm{m}^{3}$.

The polymer dispersion used was styrene-butadiene rubber (SBR) latex from BASF. The SBR latex is in a liquid state of low viscosity, having total solids content of $40.0, \mathrm{a} \mathrm{pH}$ value of 10.5 , a density of 1.01 .

\section{Preparation of Specimens}

In this study, prisms $150 \times 150 \times 600 \mathrm{~mm}$ over span of $450 \mathrm{~mm}$ were cast for flexural strength test. Before casting, coarse aggregate, sand, silica fume and water blend was mixed. Then cement, SBR latex, water put in the mixer. Finally, supper-plasticizer was added. The mixed concrete cast in molds and full compacted. The concrete mixture parameters were two different water-binder ratios $(0.35$, $0.45)$, four different SBR dosages $(0,5,10$, and $15 \%)$ and four partial replacement ratios of silica fume $(0,5,7.5$, and $10 \%)$. The specimens were subjected to the following three different curing systems:

1. 7-day water curing at $20{ }^{\circ} \mathrm{C}$ and 53 -day dry curing at $20{ }^{\circ} \mathrm{C}(7 \mathrm{~W} 53 \mathrm{D})$.
2. 14-day water curing at $20{ }^{\circ} \mathrm{C}$ and 46 -day dry curing at $20{ }^{\circ} \mathrm{C}(14 \mathrm{~W} 46 \mathrm{D})$.

3. 28-day water curing at $20{ }^{\circ} \mathrm{C}$ and 32-day dry curing at $20{ }^{\circ} \mathrm{C}(28 \mathrm{~W} 32 \mathrm{D})$.

The cement hydration and polymer film in the modified mortars develop with prolongation cured age, which results in enhanced strength. The coherent polymer film reduces weakness in the mortars, prevents extending of tiny cracks [1].

The specimens were tested for flexural strength in the manner described in BS standard 1881-118.

\section{Test Results and Discussion}

Figures $(1,2,3,4)$ show flexural strength of samples.

\section{Effects of SBR on Flexural Strength of Concrete}

In polymer-cement ratio $[\mathrm{P} / \mathrm{C}](5 \%)$, the flexural strength of modified samples increases remarkably and maximizes,

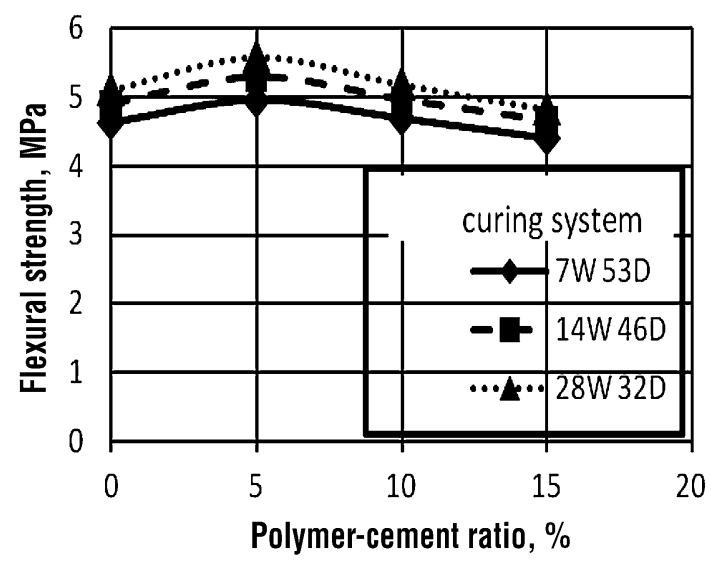

Fig. 1 Effect of polymer-cement ratio on flexural strength of concrete (w/c $=0.35$ and $0 \%$ silica fume)

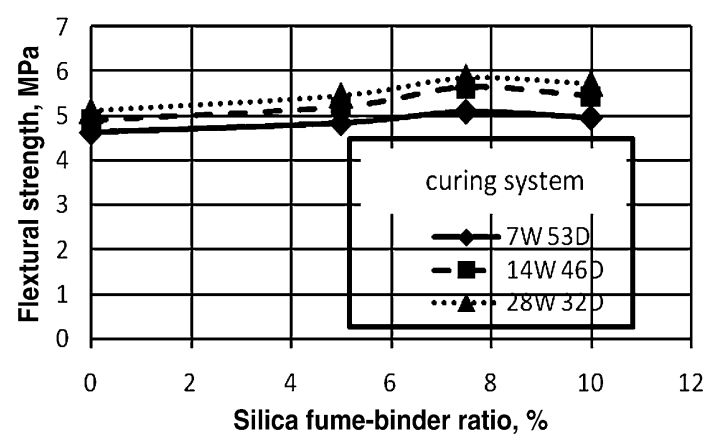

Fig. 2 Effect of silica fume-binder ratio on flexural strength of concrete $(\mathrm{w} / \mathrm{b}=0.35$ and $0 \% \mathrm{SBR})$ 


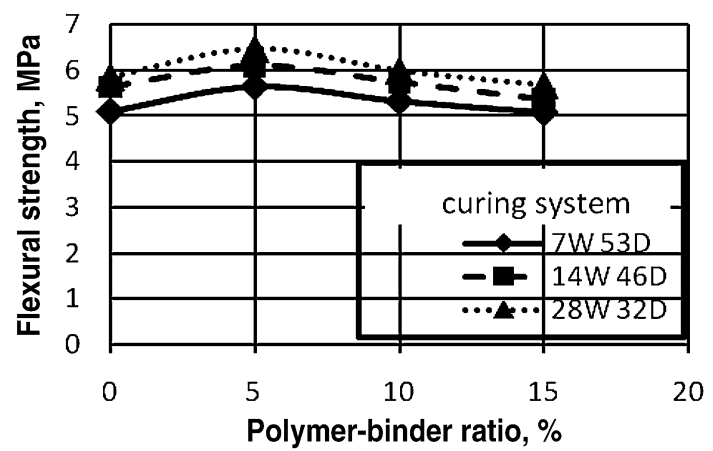

Fig. 3 Effect of polymer-binder materials ratio on flexural strength of polymer modified concrete ( $\mathrm{w} / \mathrm{b}=0.35$ and $7.5 \%$ silica fume)

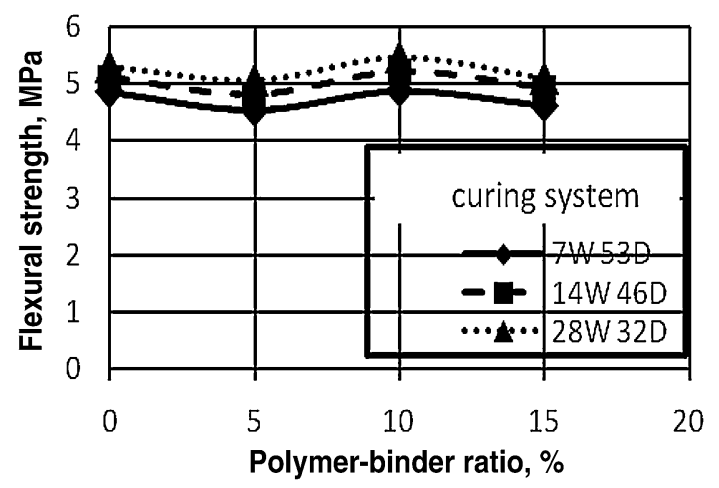

Fig. 4 Effect of polymer-binder materials ratio on flexural strength of polymer modified concrete $(\mathrm{w} / \mathrm{b}=0.45$ and $7.5 \%$ silica fume)

but with increasing polymer ratio, flexural strength decreases (Fig. 1). It seems at p/c ratio $5 \%$; the continuity is only present through small tiny bridges on a limited number of spots. The bridging and tensile performance of polymer induces such increasing. At p/c ratio $15 \%$, positive effect of polymer in increasing flexural strength is less than decreasing effect of polymer due to increasing porosity of concrete and therefore flexural strength decreases.

\section{Effects of Silica Fume on Flexural Strength}

A significant improvement in the flexural strength of concrete is observed due to high pozzolanic activity and its void filling ability of silica fume [14, 15]. The flexural strength of silica fume concrete continuously increases and maximizes at $7.5 \%$ replacement of silica fume (Fig. 2).

\section{Interfacial Effects of Silica Fume and SBR on Flexural Strength of Concrete}

The strength of concrete is affected by the ratio of SBR and silica fume to binder materials. When the ratio of polymer/ binder is certain, Silica fume increases flexural strength of concrete. Percentage of silica fume that optimizes flexural strength remains $7.5 \%$ constant (Fig. 3).

\section{Interfacial Effects of Silica Fume and SBR on Flexural Strength of Concrete}

The flexural strength of concrete is affected by the ratio of SBR and silica fume to binder materials (Fig. 3). When the ratio of polymer/binder is certain, the amount of silica fume affects strength of concrete. The percentage of silica fume that optimizes flexural strength remains $7.5 \%$.

In a few samples, a local decrease in flexural strength is observed in $5 \%$ polymer (Fig. 4). In making of these samples percentage of superplastysizer in 0 and $5 \%$ polymer were constantly considered. The cavitation of superplastysizer induces a decrease in flexural strength of these samples. (In making of these samples, the ratio of superplastysizer was kept constant.)

\section{Investigation of Main Effects and Interaction Effects of Factors in Flexural Strength}

The main effects of each factor are shown in Fig. 5. It is observed that decreasing of water to binder material from 0.45 to 0.35 increases flexural strength about $13 \%$. Averagely, $7.5 \%$ of replacement silica fume increases flexural strength about $15 \%$ and also adding $15 \%$ of SBR decreases flexural strength about $9.4 \%$.

A single interaction plot of flexural strength is shown in Fig. 6. Parallel lines in an interactions plot indicate there is

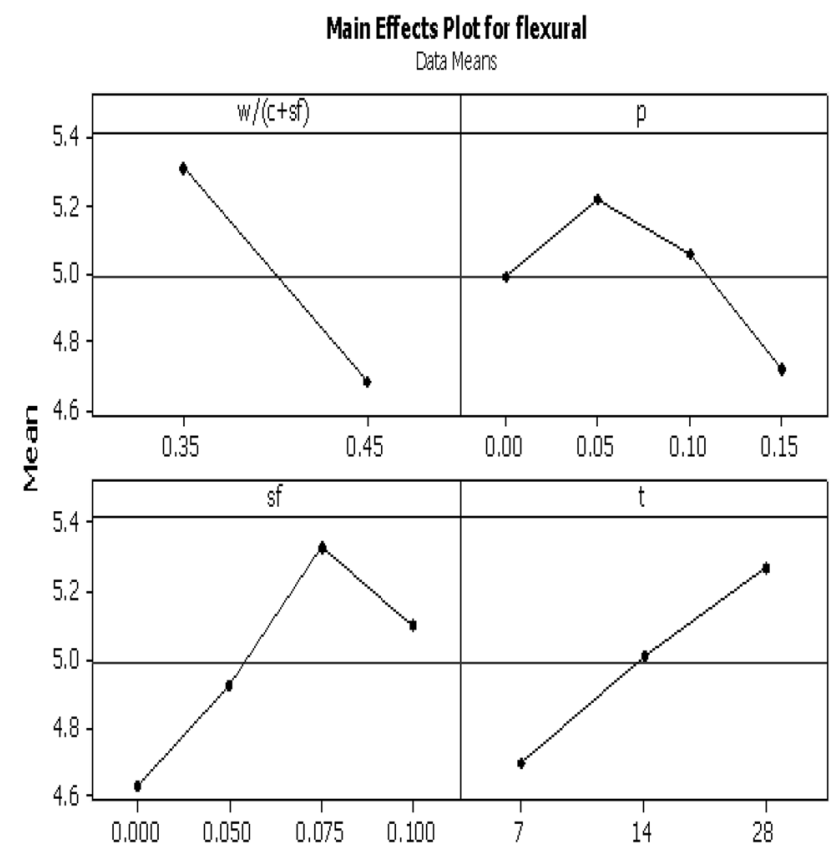

Fig. 5 Main effects of diagram for flexural strength 
Fig. 6 Interaction effects of diagram for flexural strength
Interaction Plot for flexural

Data Means

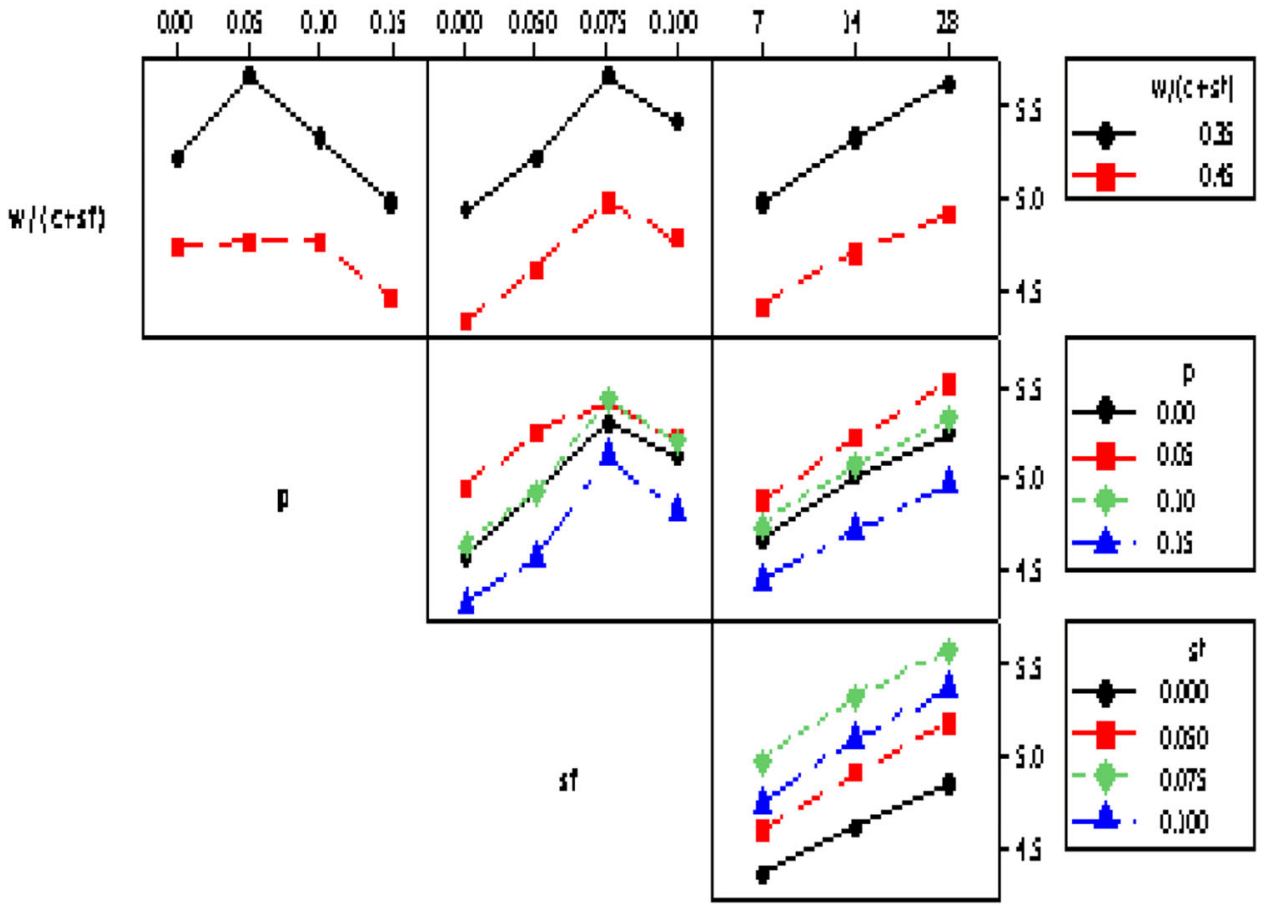

t no interaction effect between factors. The greater the departure of lines from the parallel state indicates the higher the degree of interaction, in this situation, the response at a factor level depends upon the levels of other factors. Therefore, there is no interaction effect between SBR and silica fume. Although, a decrease in flexural strength of samples with 5\% SBR and 7.5-10\% silica fume in water to binder ratio 0.45 are happening. (In making of these samples, the ratio of superplastysizer was kept constant.)

\section{Mathematical Model}

Mathematical models based on experimental data are called "free models", and are generally in regression forms. The regression forms (linear, non-linear, exponential, etc.) should be determined based on experimental data.

The primary factors that affected the flexural strength of concrete are the ratios of water, SBR, silica fume to binder materials and time of curing in water. (In modeling, from effects of superplastysizer on flexural strength is neglected.) Conventional methods of predicting flexural strength of concrete is generally based on either Abrams watercement ratio or maturity concept of concrete. Since strength development is determined not only by the water to cement ratio but also the influence of other ingredients should be investigated. Therefore, scatter diagrams are prepared and means of values are portrayed in diagrams. A lot of researchers introduce relationship between flexural strength and time of curing in water with a logarithmic equation $[15,16]$.

The scatter diagrams for all of the specimens exhibited a nonlinear relationship between the flexural strength with the ratios of silica fume and SBR to binder materials. From the scatter diagrams, it was observed that a two degree parabolic might be appropriate for showing the effect of silica fume or SBR in flexural strength of concrete. The relationship of flexural strength with each variable is shown in Figs. 7, 8, 9. The relationship between flexural strength with each factor is determined based on regression.

The relationship between flexural strength with considered variables may be represented by:

$$
\begin{aligned}
\mathrm{f}_{1}= & \mathrm{A} *(0.958 * \log (\mathrm{t})+3.896)^{\mathrm{C}} *\left(-67.8 \mathrm{~s}^{2}+12.38 \mathrm{~s}\right. \\
& +4.605)^{\mathrm{D}} *\left(-57 \mathrm{p}^{2}+6.57 \mathrm{p}+5\right)^{\mathrm{E}} / \mathrm{B}^{(\mathrm{w} / \mathrm{b})}
\end{aligned}
$$

where $f_{1}$ is the flexural strength (Mpa), w/b is the ratio of water to binder materials, $t$ is the time of curing in water (day), $s$ is the ratio of silica fume to binder materials, $p$ is the ratio of SBR polymer to binder materials. A, B, C, D 
Fitted Line Plot

flexural $=3.895+0.9587 \log 10(t)$

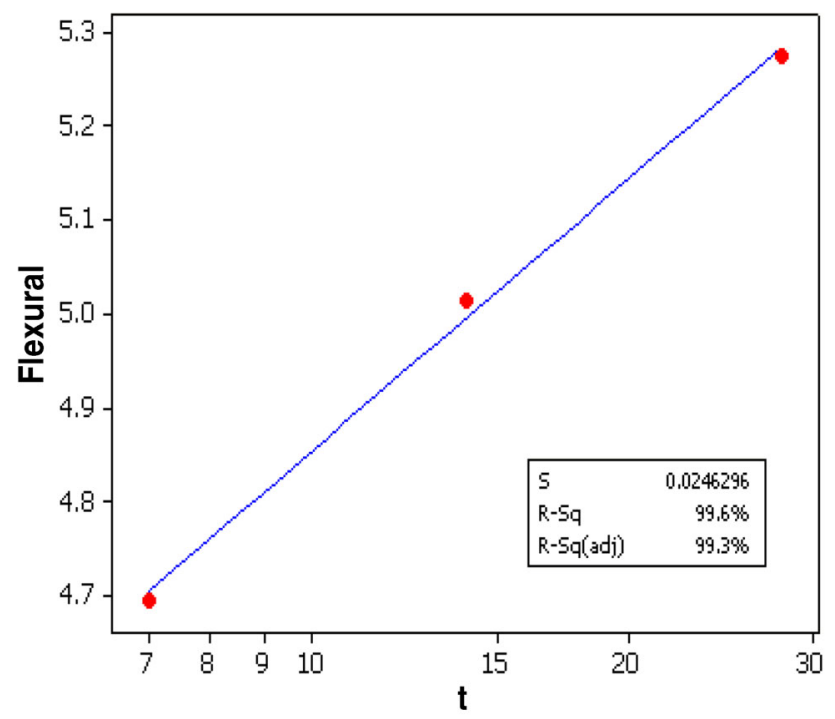

Fig. 7 Relationship between flexural strength and time of curing in water

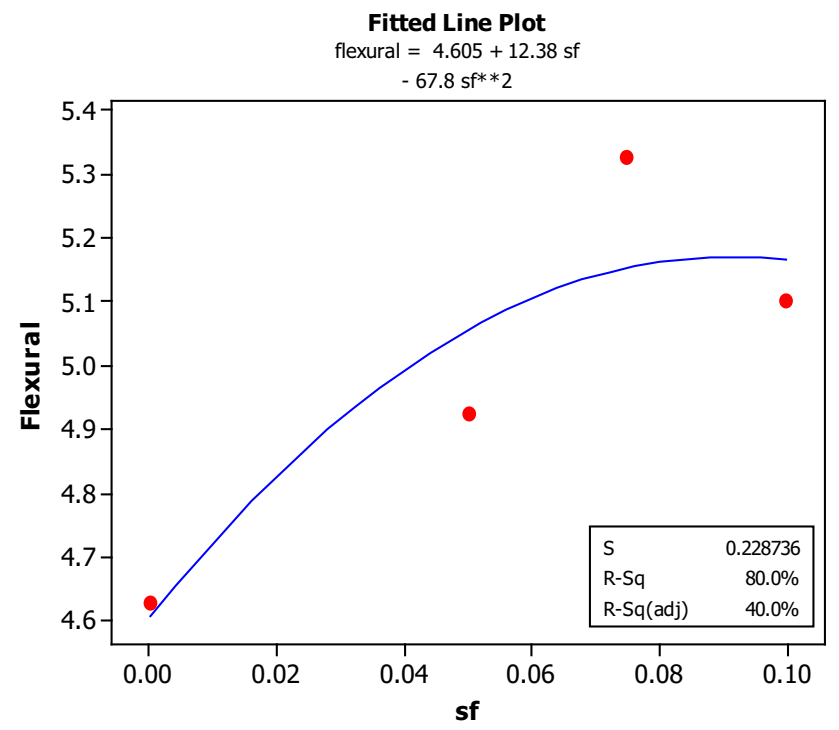

Fig. 8 Relationship between flexural strength with silica fume to binder materials ratio

and $\mathrm{E}$ are constant coefficients. The above equation can be written in the following form:

$$
\begin{aligned}
\log \left(\mathrm{f}_{\mathrm{l}}\right)= & \log (\mathrm{A})+\log (\mathrm{B}) *(\mathrm{w} / \mathrm{b})+\mathrm{C} * \log (0.958 \log (\mathrm{t}) \\
& +3.896)+\mathrm{D} * \log \left(-67.8 \mathrm{~s}^{2}+12.38 \mathrm{~s}+4.605\right) \\
& +\mathrm{E} * \log \left(-57 \mathrm{p}^{2}+6.57 \mathrm{p}+5\right)
\end{aligned}
$$

That A, B, C, D and E can be determined with multiple linear regressions. The values of these coefficients are
Fitted Line Plot

flexural $=5.001+6.570 p$ $-57.00 p * * 2$

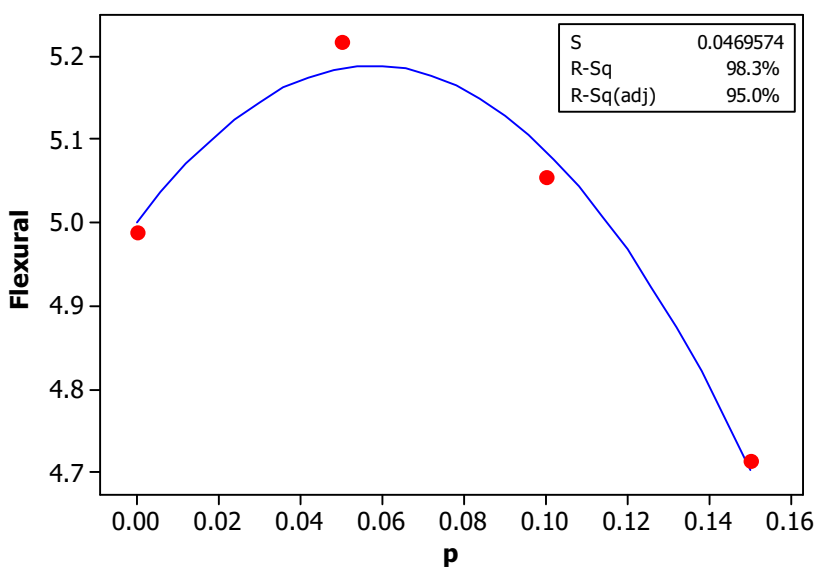

Fig. 9 Relationship between flexural strength with polymer to binder materials ratio

Table 1 Numeric values of the rate constants from Eqs. (1-2)

\begin{tabular}{lllll}
\hline A & B & C & D & E \\
\hline 2.637 & 0.999 & 0.98 & 1.01 & 0.977 \\
\hline
\end{tabular}

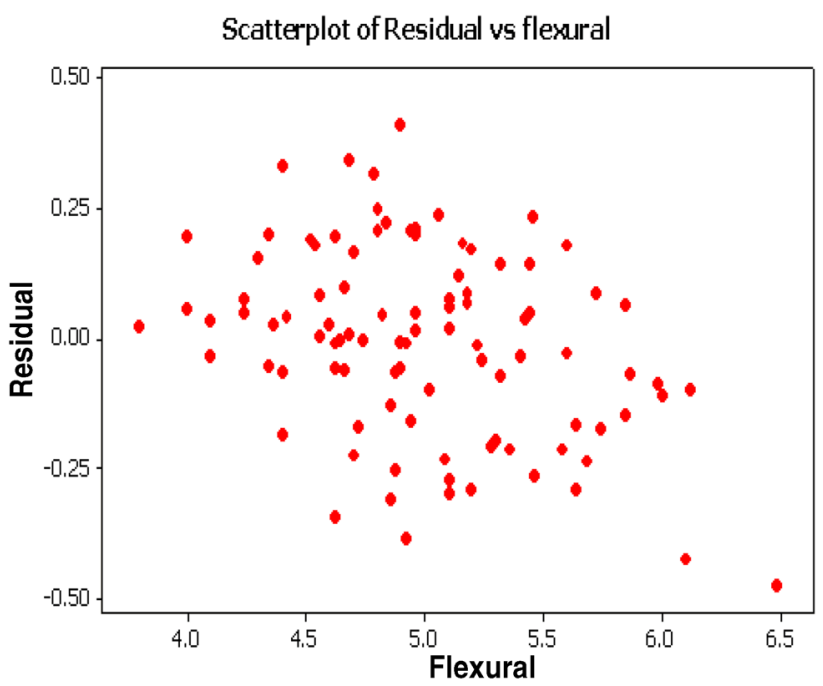

Fig. 10 Diagram of residuals for flexural strength

shown in the following table. The value of the multiple correlation coefficients ( $r$ ) has been obtained as 0.9 (Table 1).

With replacement of one to coefficients that are near one and some simplication, the following equation is obtained. 


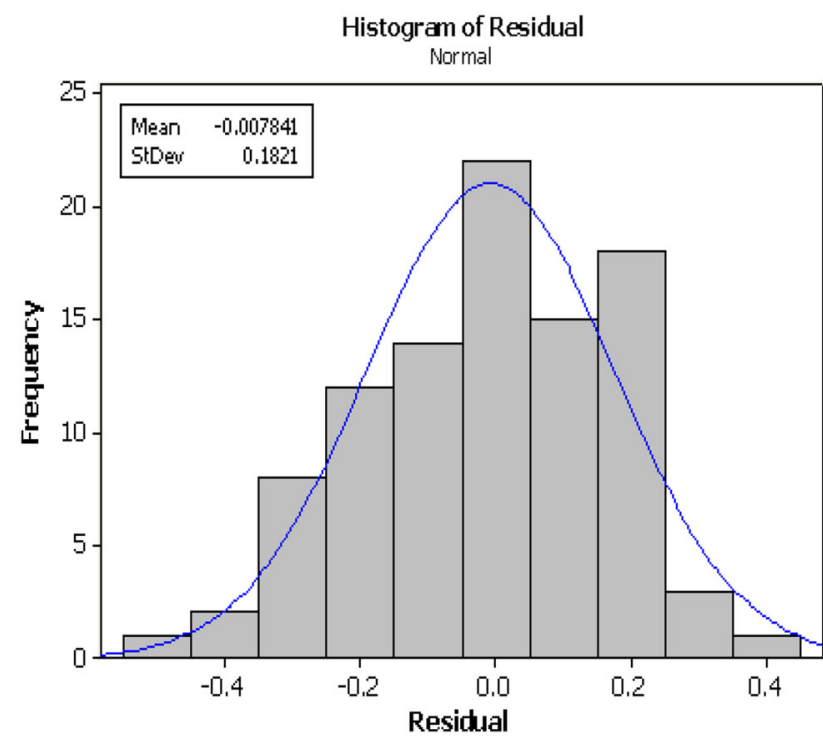

Fig. 11 Histogram of residuals for flexural strength

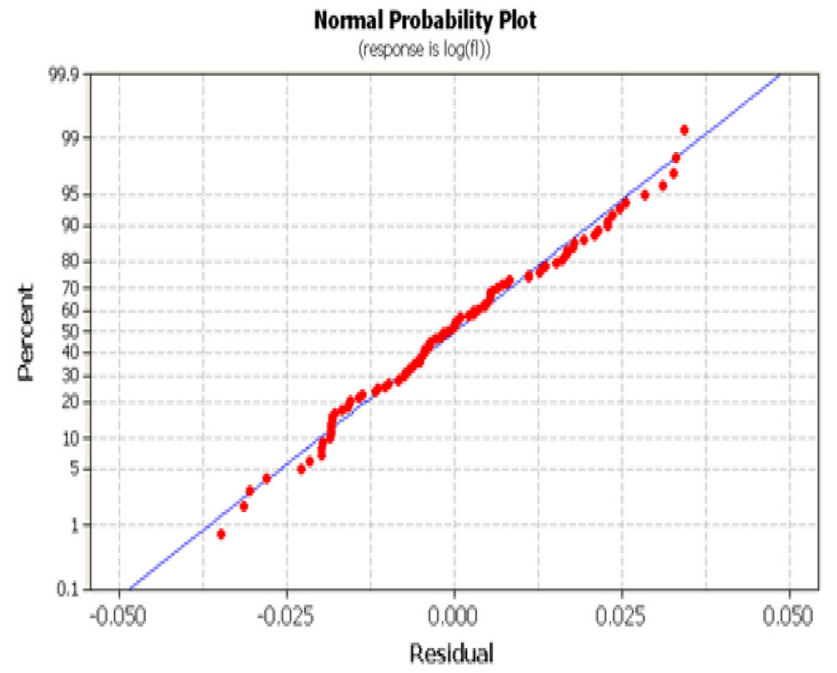

Fig. 12 Normal property plot versus residual

$$
\begin{array}{rl}
f_{1}=5.93 & *(0.246 \log (t)+1) *\left(-11.4 p^{2}+1.31 p+1\right) \\
& \times\left(-14.72 \mathrm{~s}^{2}+2.69 \mathrm{~s}+1\right) /\left[3.52^{(\mathrm{w} / \mathrm{b})}\right]
\end{array}
$$

From above equation can be determined the flexural strength of samples containing of silica fume and SBR. For investigation of the accuracy of Eq. (3), a diagram of residuals (the difference of observed and fitted values) for flexural strength has been drawn (Fig. 10). The residual diagram shows that the maximum percent error of flexural strength is $<10 \%$.
The histogram of residuals has been shown in Fig. 11. Although, the distribution residuals doesn't completely obey the normal distribution but mean and maximum values of histogram of residuals is located near zero. Also, residuals are disturbed randomly.

In Fig. 12 normal property plot versus residuals is shown. If residuals belong to a normal distribution, points should be collected around of a straight line. Here, normal property plot obey the normal probability distribution approximately, so hypothesis of normal approach is acceptable.

\section{Conclusion}

- In constant water to binder ratio and combined curing system, the flexural strength of concrete in $5 \%$ SBR rises remarkably, but with increasing polymer/binder material ratio, the flexural strength of concrete decreases.

- Cement replacement up to $7.5 \%$ with silica fume leads to maximize in flexural strength.

- The decrease of flexural strength is compensated by the reduction of $w / b$ due to the plasticizer effect of SBR. Both phenomena together remain flexural strength approximately constant.

- The percentage of silica fume that optimizes the flexural strength with adding SBR doesn't change.

- In this study, we have shown the practical acceptability of Abram's law within considered limits of SBR and silica fume and according to main effects of diagrams in each factor is proposed in the following equation:

$$
\begin{aligned}
\mathrm{f}_{1}= & 5.93 *(0.246 * \log (\mathrm{t})+1) *\left(-11.4 \mathrm{p}^{2}+1.31 \mathrm{p}+1\right) \\
& *\left(-14.72 \mathrm{~s}^{2}+2.69 \mathrm{~s}+1\right) /\left[3.52^{(\mathrm{w} / \mathrm{b})}\right]
\end{aligned}
$$

The proposed model provides the opportunity to predict the flexural strength based on the time of curing in water (t), and water, silica fume and SBR to binder materials ratios that we show with w/b, (s) and (p), briefly.

Acknowledgments The authors acknowledge the support of Shaid Rajaee University in the specimens' preparation and testing procedures.

Open Access This article is distributed under the terms of the Creative Commons Attribution 4.0 International License (http:// creativecommons.org/licenses/by/4.0/), which permits unrestricted use, distribution, and reproduction in any medium, provided you give appropriate credit to the original author(s) and the source, provide a link to the Creative Commons license, and indicate if changes were made. 


\section{References}

1. G. Barluenga, F. Hernańdez-Olivares, SBR latex modified mortar rheology and mechanical behavior. Cem. Concr. Res. 34, 527-535 (2004)

2. E.H. Hwang, Y.S. Ko, Comparison of mechanical and physical properties of SBR-polymer modified mortars using recycled waste materials. J. Ind. Eng. Chem. 14, 644-650 (2008)

3. E.H. Hwang, Y.S. Ko, J.K. Jeon, Effect of polymer cement modifiers on mechanical and physical properties of polymermodified mortar using recycled artificial marble waste fine aggregate. J. Ind. Eng. Chem. 14, 265-271 (2008)

4. R. Wang, P.M. Wang, X.G. Li, Physical and mechanical properties of styrene-butadiene rubber emulsion modified cement mortars. Cem. Concr. Res. 35, 900-906 (2005)

5. A. Beeldens, D. Van Gemert, H. Schorn, Y. Ohama, L. Czarnecki, From microstructure to macrostructure: an integrated model of structure formation in polymer-modified concrete. Mater. Struct. 38, 601-607 (2005)

6. O. Rozenbaum, R.J.M. Pellenq, H. Van Damme, An experimental and mesocopic lattice simulation study of styrene-butadiene latex-cement composites properties. Mater. Struct. 38(4), 467-478 (2005)

7. K.R. Wu, D. Zhang, J.M. Song, Properties of polymer-modified cement mortar using pre-enveloping method. Cem. Concr. Res. 32, 425-429 (2002)
8. F. Ozcan, C.D. Atis, O. Karahan, E. Uncuoğlu, H. Tanyildizi, Comparison of artificial neural network and fuzzy logic models for prediction of long-term compressive strength of silica fume concrete. Adv. Eng. Softw. 40, 856-863 (2009)

9. J.A. Rossignolo, Interfacial interactions in concretes with silica fume and SBR latex. Constr. Build. Mater. 23, 817-821 (2009)

10. Bing Chen, Juanyu Liu, Mechanical properties of polymermodified concretes containing expanded polystyrene beads. Constr. Build. Mater. 21, 7-11 (2007)

11. S. Bhanja, B. Sengupta, Influence of silica fume on the tensile strength of concrete. Cem. Concr. Res. 35, 743-747 (2005)

12. V. Bhikshma, K. Nitturkar, Y. Venkatesham, Investigations on mechanical properties of high strength silica fume concrete. Asian J. Civ. Eng. (Build. Hous.) 10(3), 335-346 (2009)

13. H. Katkhuda, B. Hanayneh, N. Shatarat, Influence of silica fume on high strength of light weight concrete. World Acad. Sci. Eng. Technol. 58, 781-788 (2009)

14. K.C. Biswal, S.C. Sadangi, Effect of Superplasticizer and Silica Fume on Properties of Concrete, in Proceedings of the International Conference on Advances in Civil Engineering (2010)

15. S. Popovics, Strength and Related Properties of Concrete a Quantitative Approach (Wiley, Hoboken, 1998)

16. P.K. Mehta, Concrete: micro structure, properties and materials. (2006) 